\title{
FRAGILIDADE AMBIENTAL E DINÂMICA GEOSSISTÊMICA: MAPEAMENTO DA PAISAGEM NA BACIA HIDROGRÁFICA DO RIO LOURENÇO VELHO, SUL DO ESTADO DE MINAS GERAIS-BRASIL
}

Thomaz Alvisi de Oliveira

Instituto Federal de Educação, Ciência e Tecnologia do Sul de Minas Gerais

Poços de Caldas, MG, Brasil

thomaz.oliveira@ifsuldeminas.edu.br

Adler Guilherme Viadana

Universidade Estadual Paulista, Departamento de Geografia

Rio Claro, SP, Brasil

adlergv@rc.unesp.br

Allan Arantes Pereira

Instituto Federal de Educação, Ciência e Tecnologia do Sul de Minas Gerais

Muzambinho, MG, Brasil,

allan.pereira@ifsuldeminas.edu.br

\begin{abstract}
RESUMO
O arranjo e organização dos mosaicos de paisagem, revelados à superfície como unidades dinâmicas concentradoras de fluxos de matéria e energia, obedecem a uma ordem de classificação definida por homogeneidades e heterogeneidades. Nas bacias hidrográficas, consideradas por lei quando do desenvolvimento de estudos de impactos ambientais, esses mosaicos expõem a relação sistêmica existente nos terrenos compreendidos por divisores topográficos sob a influência de um canal de drenagem principal e seus tributários. Esse trabalho investigou a dinâmica das unidades de paisagem na bacia hidrográfica do rio Lourenço Velho, importante referência físico-geográfica do sul do estado de Minas Gerais, utilizando a concepção geossistêmica associada à fragilidade ambiental, em duas escalas hierarquizadas de análise. A compartimentação geomorfológica e a fragilidade ambiental nortearam a classificação das unidades geossistêmicas hierarquicamente superiores e inferiores, respectivamente, e são apresentadas aqui em documento cartográfico único, contendo também, o posicionamento da paisagem em cena. Os resultados sintetizaram a relevância da fragilidade ambiental quando utilizada na investigação da dinâmica das unidades geossistêmicas de paisagem diante da substituição do quadro natural pela inserção do uso antrópico e servem como balizadores de trabalhos futuros que estejam ajustados ao planejamento do território e à gestão dos recursos hídricos.
\end{abstract}

Palavras-chave: Geossistemas. Hierarquia de classificação. Fragilidade ambiental. Meios dinâmicos. Bacias hidrográficas.

\section{ENVIRONMENTAL FRAGILITY AND GEOSYSTEMIC DYNAMIC: LANDSCAPE MAPPING IN THE LOURENÇO VELHO WATERSHED, SOUTH OF THE MINAS GERAIS STATE-BRAZIL}

\footnotetext{
ABSTRACT

The arrangement and organization of landscape mosaics, which are revealed to the surface as dynamic units concentrating flows of matter and energy, follow a classification order defined by homogeneities and heterogeneities. In watershed, that were considered by law when studies of environmental impacts, these mosaics expose a systemic relationship existing in the lands comprised by topographic dividers under the influence of a main drainage channel and its tributaries. This work investigated the dynamics of landscape units in the watershed of Lourenço Velho river, an important physical-geographic reference of the southern state of Minas Gerais, using the concept of geosystems associated with environmental fragility, in
} 
two hierarchical scales of analysis. Geomorphological compartmentalization and environmental fragility guided the classification of geosystems hierarchically higher and lower, respectively, and are presented here in a unique cartographic document, also containing the positioning of the landscape in scene. The results synthesized the relevance of the environmental fragility when used in the investigation of the geosystemic dynamics of the landscape units in face of the replacement of the natural condition for the insertion of anthropic use and serve as benchmarks for future work in alignment with territory planning and management of water resources.

Keywords: Geosystems. Hierarchy of classification. Environmental Fragility. Dynamic means. Watershed.

\section{INTRODUÇÃO}

Arranjos espaciais da superfície da Terra são fruto da interação entre os fatores abióticos e bióticos que, regidos pelo clima, se organizam sob a forma de mosaicos. Esses fatores interagindo com os elementos culturais, personificam o que é definido por Dolfuss (1973, pág. 13) como "paisagem". A paisagem é o output gerado em função da soma de processos acumulados em espaços de tempo variados, alguns em escala geológica longeva e outros na escala humana recente. Agindo sobre uma mesma área tais processos culminam em combinações homogêneas e heterogêneas que se desdobram em mosaicos de superfície e se organizam a partir da interatividade sistêmica que se soma ao longo de um espaço de tempo. Os mosaicos de paisagens podem revelar-se em unidades escalares diferenciadas e 0 reconhecimento das relações que se concretizam nesse contexto configura-se como uma das interrogações sobre o entendimento da dinâmica aí existente.

Análises integradas de fenômenos que são passíveis de observação em escalas equitativas devem atentar-se para o fato de que esses fenômenos representam a soma de outros fenômenos que se desdobram em níveis escalares hierarquicamente inferiores. Nesse contexto, a concepção geossistêmica de análise da paisagem é plausível de ser utilizada como método no estudo sobre tais fenômenos ao que se refere à sua configuração e dinamismo (Rodriguez et al., 2007; Rodriguez e Silva, 2013).

Sotchava (1956, pág. 372), definiu que a divisão físico-territorial tem por base a diferenciação dos fenômenos naturais sobre a superfície do globo abrindo amplas perspectivas à aplicação do método geográfico comparativo baseado nas semelhanças e diferenças, o que mais à frente daria conformação ao padrão bilateral de análise em geossistemas, caracterizado pelas fileiras de geômeros e geócoros. As primeiras reflexões processadas por Sotchava $(1971 ; 1974 ; 1975 ; 1977)$ sobre os geossistemas o levaram a estabelecer que os geossistemas caracterizam paisagens naturais formadas pelos elementos do meio físico e suas interações, se concretizando sob a forma de mosaicos organizados hierarquicamente na superfície, sendo que o dinamismo é uma de suas características mais importantes, independente da ordem escalar considerada (SOTCHAVA, 1978a;1978b). Junto à timeline que marca as publicações de Sotchava (op. cit.) entre os anos 60 e 90 do século XX outros pesquisadores ofereceram aporte conceitual à temática, com destaque para Yefremov (1964;1969); Saushkin (1964; 1970); Demek (1978); Bertrand (1978) e Rougerie e Beroutchachvili (1991). Destaque deve ser dado a Haase (1989) que aprofundou a explanação de Sotchava (1956) sobre as fileiras de geômeros e geócoros, explicando que as unidades geocóricas estão muito além da simples junção de unidades geométricas e sua concepção depende da extensão da unidade em análise, sendo que, na medida que a extensão em área aumenta, aumentam as complexidades e a disposição dos elementos em um espaço determinado por meio da combinação de estruturas tópicas.

Nas primeiras duas décadas do século XXI, o avanço dos métodos computacionais de análises de imagens de satélite com possibilidade de monitoramento ambiental, ofertou a possibilidade a novas contribuições no âmbito dos estudos sobre a evolução e dinâmica dos sistemas físicos-naturais dispostos e organizados na superfície, com destaque para os trabalhos de Isachenko (2007); Plyusnin et. al. (2008); Ganzei (2008) e Kuzmenko (2011). No Brasil sobressaem as comunicações de Marques Neto (2016), Marques Neto et al. (2016) e Cavalcanti e Corrêa (2017), 
Tomando como base essa atmosfera de raciocínio, a proposta geossistêmica é válida quando utilizada como recurso metodológico em estudos integrados desenvolvidos em bacias hidrográficas, uma vez que, nessa unidade de área os elementos constituintes do meio físico e antrópico encontram-se em relação sistêmica. Os trabalhos de Ganzei et al. (2010) sobre a dinâmica do uso da terra na bacia do rio Amur Daria ao longo do século XX e de Marques Neto et al. (2014), sobre os geossistemas da bacia do rio Verde, são exemplos da utilização do método geossistêmico na análise das paisagens em bacias hidrográficas. No Brasil, a bacia hidrográfica é ainda, o limite geográfico considerado em estudos sobre áreas direta e indiretamente afetadas por atividades que tragam degradação ao meio ambiente, tal como definido pela Lei n. 6.938/81, normatizada pela resolução do CONAMA 001/86 e pela Lei $n$. 9.433/97, que reza sobre o planejamento e a gestão dos recursos hídricos.

A interpretação da dinâmica da paisagem nessas unidades é factível de verificação pelo estudo integrado dos seus atributos mais característicos que traduzem as alterações dos fluxos de matéria advindos de novos inputs energéticos e que são revelados, principalmente, por outputs representados por processos erosionais e deposicionais e pela transferência, mais ou menos acentuada, das águas precipitadas para a circulação de subsuperfície. A partir dessa concepção, a fragilidade ambiental se comporta como ferramenta verificadora da dinâmica geossistêmica existente em determinada unidade de área, sendo utilizada na avaliação da dinâmica de terrenos em bacias hidrográficas (Nakashima, 2001; Oliveira et al., 2008; Batista e Silva, 2013).

Seguindo essa linha de raciocínio, apresenta-se aqui um estudo geossistêmico empregado na verificação da dinâmica da paisagem na bacia hidrográfica do rio Lourenço Velho, importante referência geoespacial do Sul do estado de Minas Gerais, dadas as suas especificidades físiconaturais sob pressão das atividades, principalmente, agrosilvopastoris. Calibrada na escala 1:100.000, a abordagem recorre aos procedimentos de mapeamento apresentados pela "escola soviética" de Geografia e utiliza a compartimentação geomorfológica e a fragilidade ambiental como elementos balizadores na definição dos mosaicos hierarquizados de paisagens e de seu dinamismo, respectivamente.

As análises desenvolvidas a partir da ótica geossistêmica integram quantidade significativa de informações e definem hierarquias de classificação para compartimentos de paisagens dentro de uma unidade de área específica, aqui representada pela bacia hidrográfica do rio Lourenço Velho. Estudos dessa envergadura servem instituições públicas e privadas que tenham seus trabalhos direcionados ao planejamento do uso e ocupação da terra, sendo também muito úteis às pesquisas ambientais como um todo.

\section{METODOLOGIA}

O trabalho se desdobrou em etapas, onde arquivos em formato shape, folhas topográficas na escala 1:50.000, editadas pelo IBGE entre 1971 e 1975 e um Modelo Digital de Elevação (MDE) derivado do sensor ASTER (Advanced Spaceborne Thermal Emission and Reflection Radiometer) ofertado gratuitamente pela NASA (2017), meridiano central de $45^{\circ} \mathrm{W}$ e resolução espacial de $30 \times 30$ metros auxiliaram a extração das informações morfométricas e morfográficas, apoiaram a elaboração dos documentos cartográficos de caracterização e a compartimentação geomorfológica da área. Além disso subsidiaram orientações para as atividades desenvolvidas em campo.

Um inventário pré-paisagístico ajustado à escala trabalhada foi elaborado e expresso pela litoestrutra (CPRM 2006;2008), solos (CAVALCANTE et al., 1979; UFV, 2010) morfometria e uso e ocupação da terra. Um esboço cartográfico referente à configuração da vegetação nativa (IBGE, 1992; 2004) na área e à intensidade de radiação incidente à superfície, firmaram-se como informações de apoio às análises posteriores. Quando necessário, as adequações 
escalares se processaram com o apoio da bibliografia cartográfica pré-existente e calibradas com atividades em campo.

Para o mapeamento e caracterização do uso e ocupação da terra, foram utilizadas imagens do sensor Landsat 5, com resolução espacial de $30 \times 30$ metros. A classificação foi realizada com base nos dados de refletância da superfície, nas faixas de comprimentos de ondas do Azul $(0,4$ $\mu \mathrm{m})$; Verde $(0,5 \mu \mathrm{m})$; Vermelho $(0,7 \mu \mathrm{m})$, Infravermelho próximo $(0,8 \mu \mathrm{m})$, infravermelho de ondas curtas $1(1,6 \mu \mathrm{m})$ e Infravermelho de ondas curtas $2(2,1 \mu \mathrm{m})$. Estes dados correspondem as bandas $1,2,3,4,5$ e 7, respectivamente. A elaboração do mapa de uso e ocupação da terra se deu por meio de segmentação automática, seguido de classificação supervisionada utilizando o método Support Vector Machine. Para tanto, foram coletadas amostras das classes de interesse, que serviram para a caracterização espectral de cada classe. As classes de uso consideradas foram: solo exposto, pastagem, agricultura, reflorestamento, floresta nativa e campos de altitude.

O mapa de compartimentos geomorfológicos foi elaborado a partir da associação das informações geológico-estruturais àquelas hipsométricas, de declividades e de orientação das vertentes, estas últimas adquiridas pela interpretação da cena ASTER com apoio de software GIS específico. A hipsometria foi obtida pelo método de reclassificação manual, culminando na adoção de onze classes hipsométricas com diferenças altimétricas de 150 metros. Os dados de declividade, calibrados em graus, foram obtidos pela leitura da inclinação das rampas e os resultados distribuídos em cinco classes balizadas entre inferiores a cinco graus $\left(<5^{0}\right)$ e superiores a quarenta e cinco graus $\left(>45^{\circ}\right)$. Os dados referentes à orientação das vertentes foram levantados por leitura angular da exposição das faces frente à orientação azimutal inicial e calibrados para os quadrantes Norte (N: $\left.337,5^{\circ}-22,5^{\circ}\right)$, Nordeste (NE: $\left.22,5^{\circ}-67,5^{\circ}\right)$, Leste (L: $\left.67,5^{\circ}-112,5^{\circ}\right)$, Sudeste (SE: $\left.112,5^{0}-157,5^{\circ}\right)$, Sul (S: $\left.157,5^{\circ}-202,5^{\circ}\right)$, Sudoeste (SW-202, $5^{0}$ $247,5^{\circ}$ ), Oeste $\left(0: 247,5^{0}-292,5^{0}\right)$ e Noroeste (NW: $\left.292,5^{0}-337,5^{\circ}\right)$. Esses dados foram integrados à análise do padrão de formas, por meio das quebras positivas e negativas na cena ASTER e do comportamento da rede de drenagem e das curvas de nível nas cartas topográficas, respectivamente seguindo as orientações de Soares e Fiori (1976), Ross (1992) e IBGE (2009), para a elaboração do mapa de compartimentos geomorfológicos. Como resultado foram definidos seis compartimentos, individualizados em agradacionais e degradacionais.

A fragilidade ambiental foi avaliada com apoio dos pressupostos teóricos e metodológicos de Ross (1994) e Nakashima (2001). A análise integrada das variáveis apoiou-se nas etapas de sistemática de referência espacial, processamento da intersecção geométrica e procedimento de combinação dos atributos. Meirelles et al. (2007) explicam que esse método permite a minimização dos erros de classificação que possam se fazer presentes quando os valores atribuídos a uma variável em determinada localização "não satisfizerem aos requisitos de uma determinada classe" (MEIRELLES et al., 2007, pág. 117). Uma vez tomada como o produto das alterações provenientes da transformação do uso da terra, a fragilidade ambiental vincula-se à dinâmica dos terrenos quando analisada sob a ótica sistêmica com foco na relação existente entre morfogênese e pedogênese, tal como apontado por Ross (1994).

Para a composição do mapa de fragilidade ambiental foram utilizadas informações sobre os atributos de declividade, uso da terra e solos. A variável declividade foi considerada o dígito principal por conta da sua expressividade e amplitude na área. A ela seguiram-se os mapas de uso e ocupação da terra e solos, em sequência foram atribuídos pesos e qualificadores a cada uma das classes dos atributos selecionados. As variáveis utilizadas para gerar o mapa de fragilidade ambiental, bem como seus respectivos pesos e qualificadores, estão expressos na Tabela 1. 
Tabela 1 - Relação entre os atributos considerados e as classes de Fragilidade Ambiental da bacia hidrográfica do rio Lourenço Velho.

\begin{tabular}{|c|c|c|c|c|}
\hline \multicolumn{3}{|c|}{ Atributos } & \multirow[b]{2}{*}{ Pesos } & \multirow{2}{*}{$\begin{array}{l}\text { Classes de } \\
\text { Fragilidade }\end{array}$} \\
\hline Declividade & Uso da Terra & Solos & & \\
\hline$<5^{0}$ & $\begin{array}{c}\text { Floresta Nativa / } \\
\text { Campos de Altitude }\end{array}$ & - & 1 & Muito Baixa \\
\hline $51-15^{0}$ & Reflorestamento & - & 2 & Baixa \\
\hline $15 \mathrm{I}-25^{0}$ & Pastagem & $\begin{array}{l}\text { Argissolo Vermelho / } \\
\text { Argissolo Vermelho- } \\
\text { Amarelo }\end{array}$ & 3 & Média \\
\hline $251-45^{u}$ & Culturas Agrícolas & Cambissolos & 4 & Alta \\
\hline$>45^{\circ}$ & Solo Exposto & $\begin{array}{l}\text { Neossolos Flúvicos; } \\
\text { Neossolos Litólicos }\end{array}$ & 5 & Muito Alta \\
\hline
\end{tabular}

Para gerar a cartografia das unidades geossistêmicas, alocada no nível Topológico de análise, utilizou-se as informações prestadas pelo trabalho de compartimentação geomorfológica que posteriormente foram somadas àquelas apresentadas pela fragilidade ambiental da área, refinadas com os dados levantados na caracterização pré-paisagística.

O posicionamento das unidades geossistêmicas superiores, resultado da compartimentação geomorfológica da área, foi emparelhado, na fileira dos geômeros, ao táxon classe de fácies e as unidades inferiores ao táxon grupo de fácies. A expressão dinâmica dessas unidades é função das informações advindas da fragilidade ambiental.

$\mathrm{Na}$ fileira dos geócoros as unidades superiores compuseram o táxon topogeócoro e as inferiores o mesogeócoro. A fileira de geômeros expõe a individualidade de cada uma das unidades e a fileira dos geócoros unifica tais unidades em complexos dinâmicos.

\section{RESULTADOS E DISCUSSÃO \\ CENÁRIO FISIOGRÁFICO DA BACIA HIDROGRÁFICA DO RIO LOURENÇO VELHO}

A bacia do rio Lourenço Velho é unidade hidrográfica de importância regional no contexto sul do estado de Minas Gerais, sendo parte integrante da bacia hidrográfica do rio Grande. Revelase inserida na serra da Mantiqueira, onde amplitudes topográficas consideráveis e declividades acentuadas impõem grande potencial erosivo por movimentos gravitacionais, e conferem ao escoamento pluvial papel importante no entalhe da superfície. De Martonne (1943, págs. 7173) destacou a preponderância da estrutura em relação à morfologia nas serras do Mar e Mantiqueira e a desigualdade de resistência entre granitos e gnaisses, fato que acaba por orientar o entalhe das drenagens, ao valerem-se das zonas de menor resistência dessas rochas. Lineamentos estruturais influenciam a configuração e a orientação dos vales e topos de interflúvios e os contatos entre litologias graníticas e gnáissicas são elementos orientadores dos padrões fluviais e do alinhamento das cristas, condicionando a eles aspecto retilinizado.

A relação entre a estrutura e a morfologia é perceptível pela predominância de lineamentos a $\mathrm{NE} / \mathrm{SW}$, os quais, subsidiaram o posicionamento de superfícies escalonadas. $\mathrm{O}$ trabalho desenvolvido por Magalhães Júnior e Diniz (1997) contextualizou de forma detalhada a relação entre as principais direções dos sistemas estruturais e o fatiamento do relevo em cristas que acompanham tais lineamentos.

O mapa de compartimentos geomorfológicos da bacia hidrográfica do rio Lourenço Velho é a resposta sistêmica à integração das variáveis litoestruturais e morfométricas e expõe um complexo de morfologias degradacionais que contracenam com a planície fluvial da drenagem principal, relevo de agradação mais evidenciado na escala trabalhada (Figura 1). 
Fragilidade ambiental e dinâmica geossistêmica: mapeamento da paisagem na bacia hidrográfica do Rio Lourenço Velho, sul do estado de Minas Gerais-Brasil
Thomaz Alvisi de Oliveira Adler Guilherme Viadana Allan Arantes Pereira

Figura 1 - Mapa de compartimentos geomorfológicos da bacia hidrográfica do rio Lourenço Velho, Sul do estado de

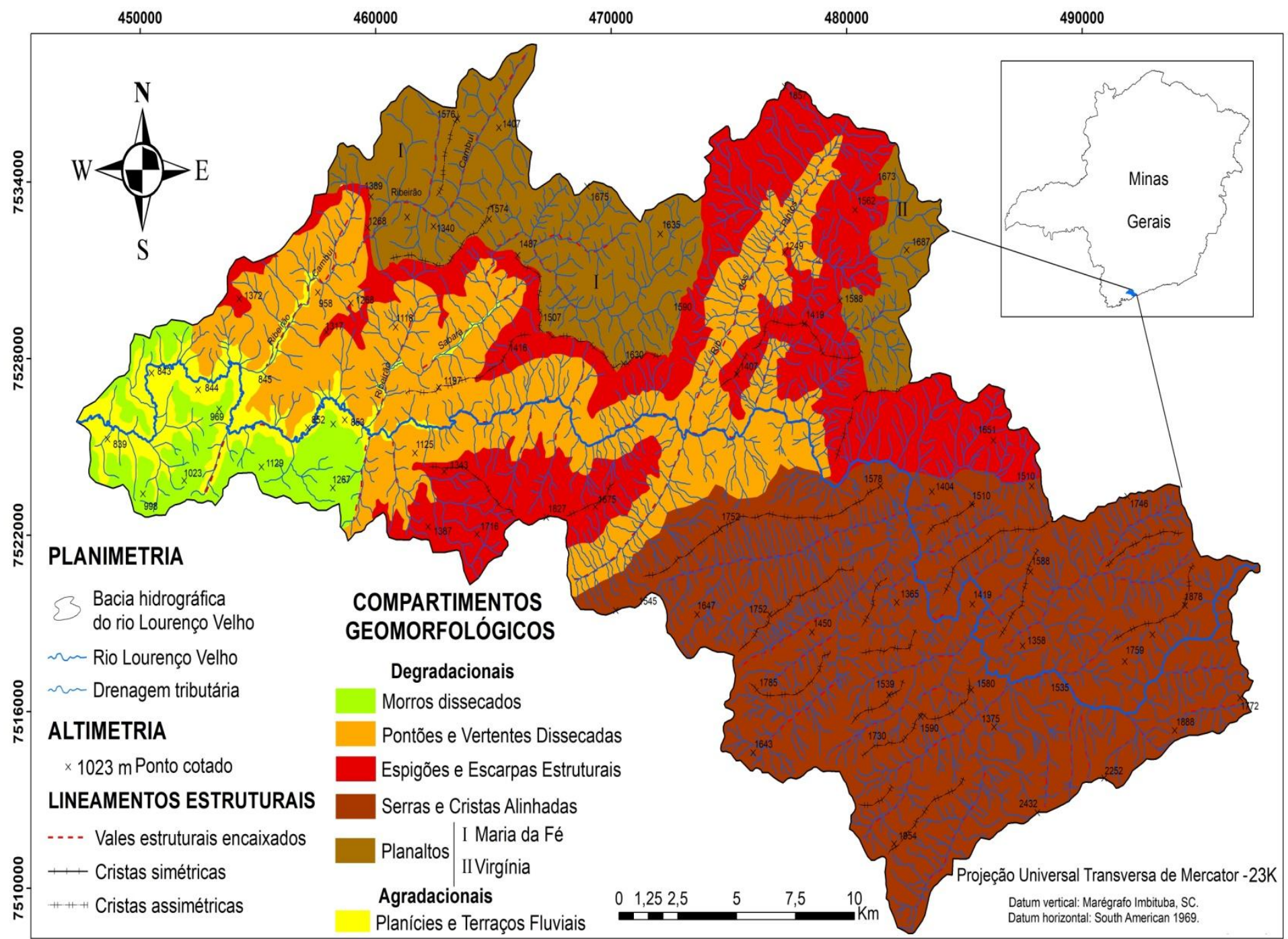

Cambissolos háplicos, argissolos vermelhos e argissolos vermelho-amarelos se intercalam espacialmente na bacia, destacando-se em expressividade dos demais grupos. Neossolos flúvicos e gleissolos ocorrem associados à planície fluvial da drenagem principal coalescendo com as planícies de ribeirões tributários. Neossolos litólicos, alocam-se nas porções oeste e norte da bacia (UFV, 2010).

O uso da terra caracteriza-se pelos cultivos temporários, com destaque para a batata, o arroz, a cebola e o tomate; e cultivos permanentes dentre os quais adquirem destaque a bananicultura, a cafeicultura e as culturas frutíferas. Pastagens cobrem boa parte da área e tal como a bananicultura e a cafeicultura, são presentes por grandes extensões outrora cobertas pelas Florestas Ombrófila Montana, Ombrófila Mista Montana e Alto Montana, segundo dados do IBGE (1992). Áreas de pinheirais ainda preservadas, compostas por Araucária angustifólia e Podocarpos lamberti, encontram-se fixadas junto às vertentes mais úmidas ou em Reservas Particulares do Patrimônio Natural (RPPN's) e outras reservas de proteção à biodiversidade. Campos de altitude alocam-se em porções mais elevadas da bacia, principalmente junto aos setores leste/sudeste.

Tal como aferido por Ross (1994), a fragilidade ambiental vincula-se diretamente à dinâmica dos terrenos quando analisada sob a ótica sistêmica com foco na relação existente entre morfogênese e pedogênese. Essa dinâmica é consonante com o cenário encontrado na bacia hidrográfica do rio Lourenço Velho, tal como exposto pela Figura 2. 
Fragilidade ambiental e dinâmica geossistêmica: mapeamento da paisagem na bacia hidrográfica do Rio Lourenço Velho, sul do estado de Minas Gerais-Brasil
Thomaz Alvisi de Oliveira Adler Guilherme Viadana Allan Arantes Pereira

Figura 2 - Expressão dinâmica da paisagem em uma porção da bacia hidrográfica do rio Lourenço Velho em função da relação entre o uso dado à terra e a morfogenia e pedogenia dos ambientes.

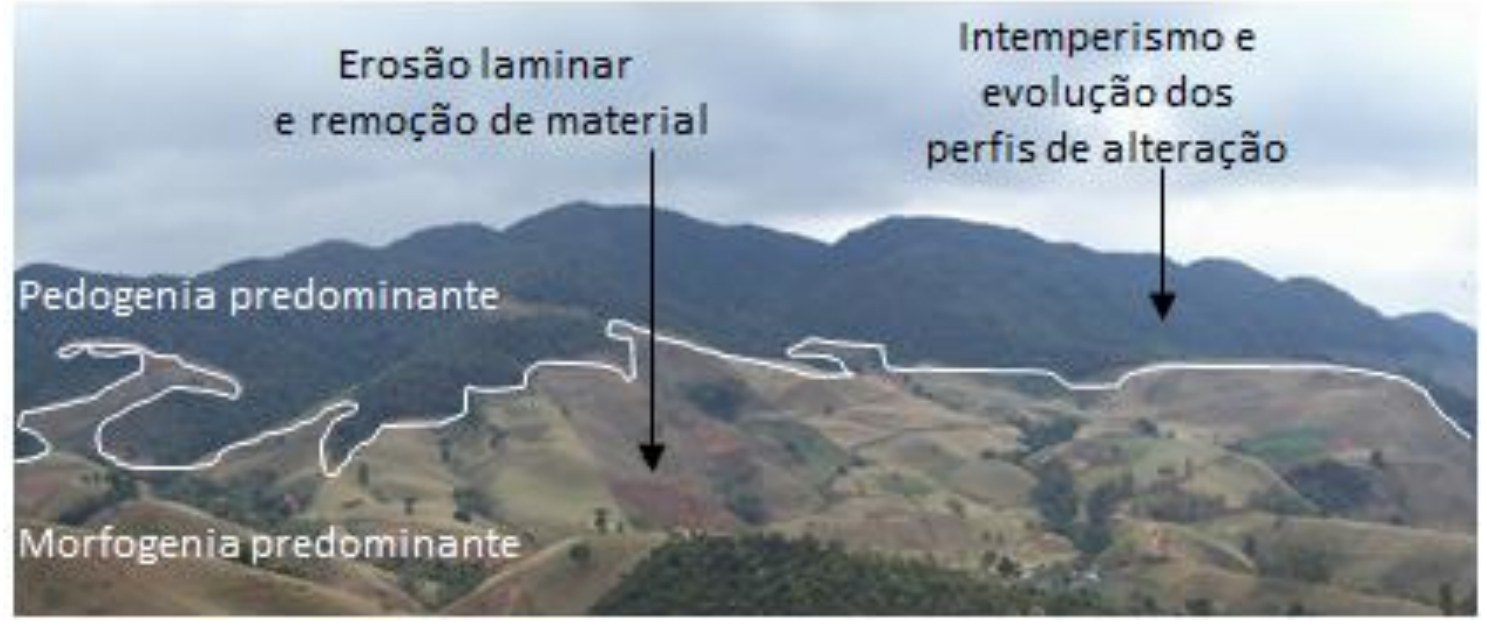

Elaboração - Os Autores.

Na unidade de área ora considerada, a paisagem é resultante da união dos elementos naturais sob intervenção dos elementos antrópicos, representados pelas atividades agrosilvopastoris. A dinâmica dessa relação é expressa pelo mapa de fragilidade ambiental por meio da oscilação das classes, resposta sistêmica derivada do potencial ao estanque, à ativação ou, ainda, à reativação de processos desencadeados frente a reorganização de inputs e outputs no sistema. (Figura 3)

Figura 3 - Mapa de fragilidade ambiental da bacia hidrográfica do rio Lourenço Velho, Sul do estado de Minas Gerais.

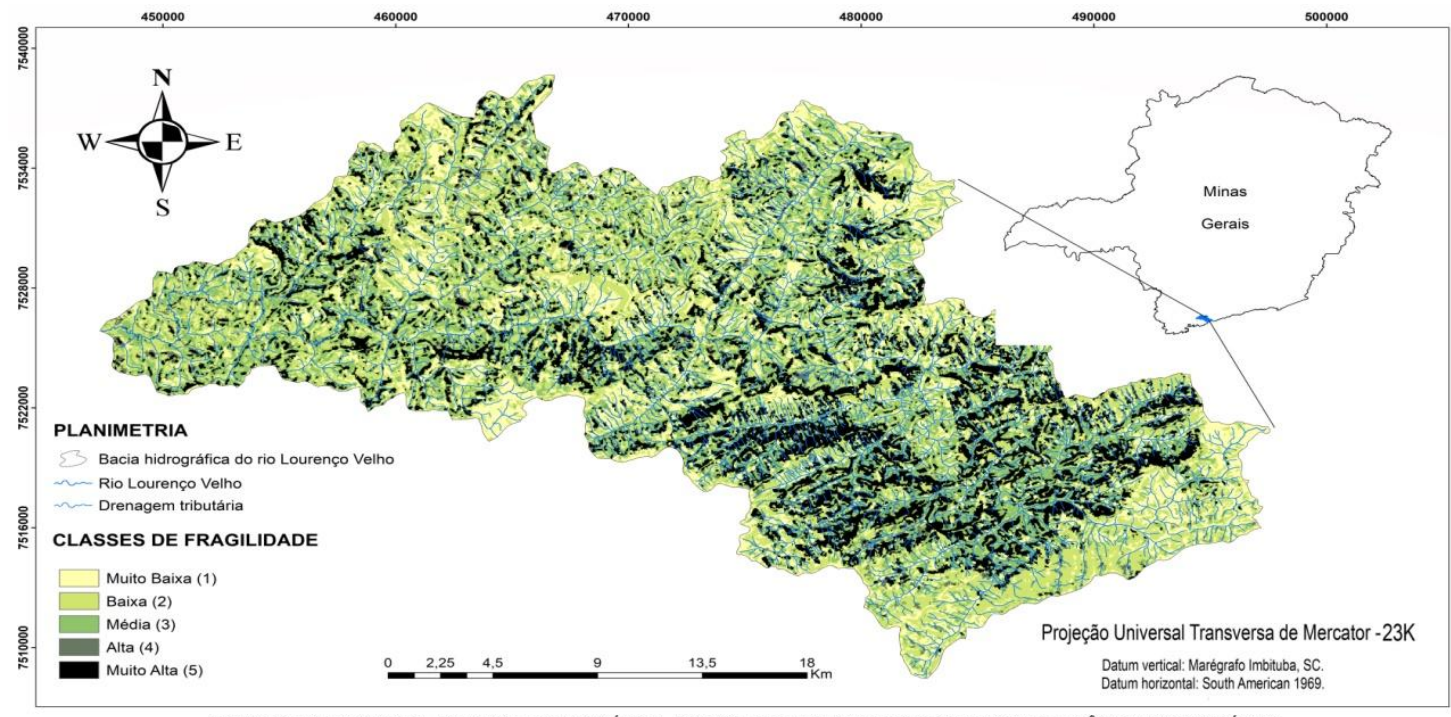

FRAGILIDADE AMBIENTAL DA BACIA HIDROGRAFICA DO RIO LOURENÇO VELHO SEGUNDO A RELEVÃNCIA DAS VARIAVEIS

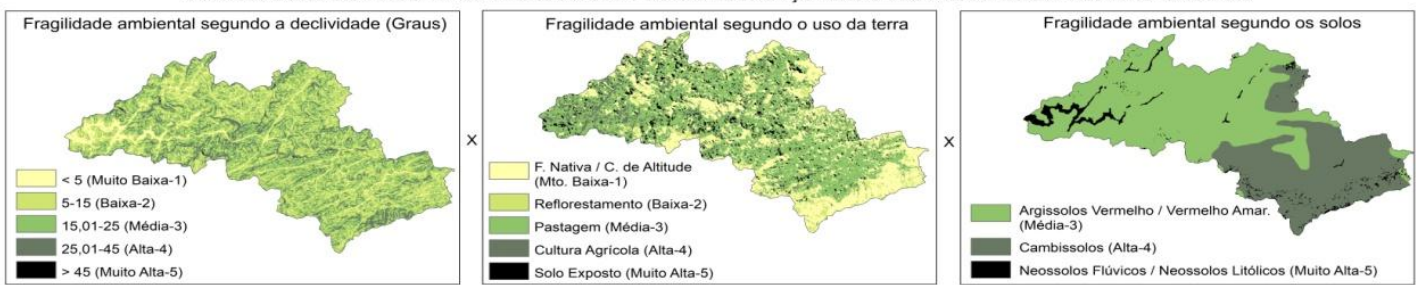

Fonte: $\mathrm{O}$ autor 


\section{O FUNCIONAMENTO SISTÊMICO DA PAISAGEM NA BACIA HIDROGRÁFICA DO RIO LOURENÇO VELHO: CLASSE DE FÁCIES/TOPOGEÓCOROS E GRUPOS DE FÁCIES/MESOGEÓCOROS}

O funcionamento das unidades geossistêmicas no cenário hierárquico superior, tanto para a fileira dos geômeros quanto para a fileira dos geócoros foi balizado pelas relações que se processam entre os elementos que mais se evidenciam nessas unidades.

Os compartimentos geomorfológicos, nesse interim, correspondem a unidades geossistêmicas com processos específicos que interagem em função dos elementos que os caracterizaram. Sob essa ótica, os limites das unidades superiores encontram-se justapostos aos limites definidos pela compartimentação geomorfológica, e que representam classes de fácies na fileira dos geômeros, e personificam um topogeócoro na fileira dos geócoros. O dinamismo aí existente, definido a partir da fragilidade ambiental, advém da reorganização das unidades superiores em subunidades, as quais definem os grupos de classes, na fileira dos geômeros, sendo que, o conjunto dessas unidades, com todas as suas heterogeneidades, conceitua um mesogeócoro. É dessa forma que os dados de fragilidade ambiental contracenam com as unidades geossistêmicas e personificam a dinâmica da paisagem na bacia hidrográfica do rio Lourenço Velho.

O dinamismo de cada uma as unidades de paisagem mapeadas como classe de fácies e a individualização das mesmas em grupos de fácies pode ser melhor entendido quando os resultados são interpretados, individualmente, em cada uma das unidades balizadas no táxon classe de fácies.

Assim, na classe de fácies denominada "Planícies e Terraços", sob forte influência da dinâmica hídrica, dois grupos de fácies se destacaram: um caracterizado por unidades originalmente recobertas pela floresta Ombrófila Densa Montana e que atualmente encontram-se sob o uso de pastagem e outro, por áreas recobertas originalmente pela floresta Ombrófila Densa Montana e que atualmente encontram-se sob a intervenção de culturas agrícolas/solo exposto. Uso e ocupação da terra foi a variável de relevância na classe de fácies ora considerada, denunciando que, com a necessidade de preparo sazonal da terra para uso agrícola a fragilidade ambiental aumenta consideravelmente. A dinâmica que se processa nesses dois grupos de fácies relaciona-se à existência ou não de cobertura fixa do solo e à sazonalidade das precipitações e vazões dos canais de drenagem, sendo expressa pelos trabalhos de remoção e deposição dos materiais disponíveis à superfície.

Para a classe de fácies "Morros Dissecados" foram identificados e diferenciados dois grupos de fácies representados por terrenos recobertos originalmente pela vegetação nativa (Ombrófila Densa Montana e Ombrófila Mista Alto-Montana) sob o uso atual de pastagens e sob o uso atual culturas agrícolas/solo exposto, respectivamente. Declividade e uso da terra foram as variáveis que balizaram a fragilidade ambiental da unidade considerada, alertando que a dinâmica nesses mosaicos advém da instalação de processos erosivos laminares nas áreas de uso agrícola, oferecendo carreamento direto dos materiais à superfície em direção aos terrenos contextualizados na classe de fácies definida como Planícies e Terraços.

"Pontões e Vertentes Dissecadas" é uma classe de fácies representada por superfícies rebaixadas por escalonamento tectônico onde dois grupos de fácies caracterizados pelos mosaicos compostos por fitofisionomias nativas e pelos mosaicos outrora compostos por essas mesmas fitofisionomias e hoje ocupados em grande parte por pastagens e cultivos agrícolas se individualizam. Esses dois grupos de fácies possuem classes de fragilidade ambiental diferenciadas e a declividade e o uso e a ocupação da terra foram as variáveis preponderantes para tal diferenciação. A dinâmica dessas áreas está vinculada à utilização da terra pelos cultivos agrícolas e pastagens nas porções mais declivosas, propiciando a instalação de processos erosivos laminares e lineares decorrentes da potencialização dos fluxos pluviais.

"Espigões e Escarpas Estruturais" é a classe de fácies onde a vegetação nativa representada pelas Florestas Ombrófila Densa Montana e Mista Alto Montana resiste nas cotas mais elevadas e vertentes mais declivosas como mosaicos sob a forte pressão das atividades agrosilvopastoris. Dois grupos de fácies se destacaram no âmbito dessa classe de fácies: um caracteriza áreas originalmente recobertas por Vegetação Nativa e outro, áreas recobertas por 
Fragilidade ambiental e dinâmica geossistêmica: mapeamento da paisagem na bacia hidrográfica do Rio Lourenço Velho, sul do estado de Minas Gerais-Brasil
Thomaz Alvisi de Oliveira Adler Guilherme Viadana Allan Arantes Pereira

Vegetação Nativa sob uso atual de pastagem e culturas agrícolas. As variáveis uso da terra e declividade foram aquelas que interferem de forma mais incisiva na dinâmica dessa unidade. A presença da vegetação nativa é preponderante para a alimentação da circulação de subsuperfície, garantindo a vazão dos canais de drenagem, nos períodos de estiagem.

$\mathrm{Na}$ classe de fácies "Planaltos", composta por terrenos alçados a cotas altimétricas que se destacam das porções de flanco, três grupos de fácies se fizeram presentes. O primeiro referese às áreas onde as fitofisionomias nativas persistem em extensão, o segundo destaca áreas onde a utilização da terra se faz pelas atividades pastoris e o terceiro onde o uso se dá pelas culturas agrícolas temporárias com expressividade para a bataticultura e onde, manchas de solo exposto formam mosaicos expressivos. Uso da terra e declividade foram as variáveis que melhor representaram as classes de fragilidade ambiental dessa unidade geossistêmica. Nas áreas sob uso agrícola são observados processos erosivos, principalmente laminares, que conduzem boa parte do material exposto à superfície para as drenagens que funcionam como nível de base para essas áreas, sendo visíveis processos de sedimentação e colmatação dos seus leitos.

Dois grupos de fácies se distinguem na Classe de fácies "Serras e Cristas Alinhadas": áreas recobertas pela vegetação nativa e áreas originalmente recobertas por essa mesma vegetação porém, sob uso atual de pastagens. Declividades e uso da terra foram as variáveis que mais influenciaram a fragilidade ambiental dessas áreas e a dinâmica aí existente está relacionada à alteração dos fluxos de energia mediante a substituição da vegetação nativa por cultivos e pastagens, elevando as classes de fragilidade ambiental.

Os resultados finais são representados em um documento cartográfico que integra as informações referentes ao enquadramento das unidades geossistêmicas, relacionando as unidades geométricas e geocóricas definidas a partir da leitura integrada das informações geomorfológicas e de fragilidade ambiental, além do posicionamento da paisagem em cena, caracterizado pelos principais tipos de uso dessas unidades (Figura 4).

Figura 4 - Enquadramento da paisagem da bacia hidrográfica do rio Lourenço Velho e seu
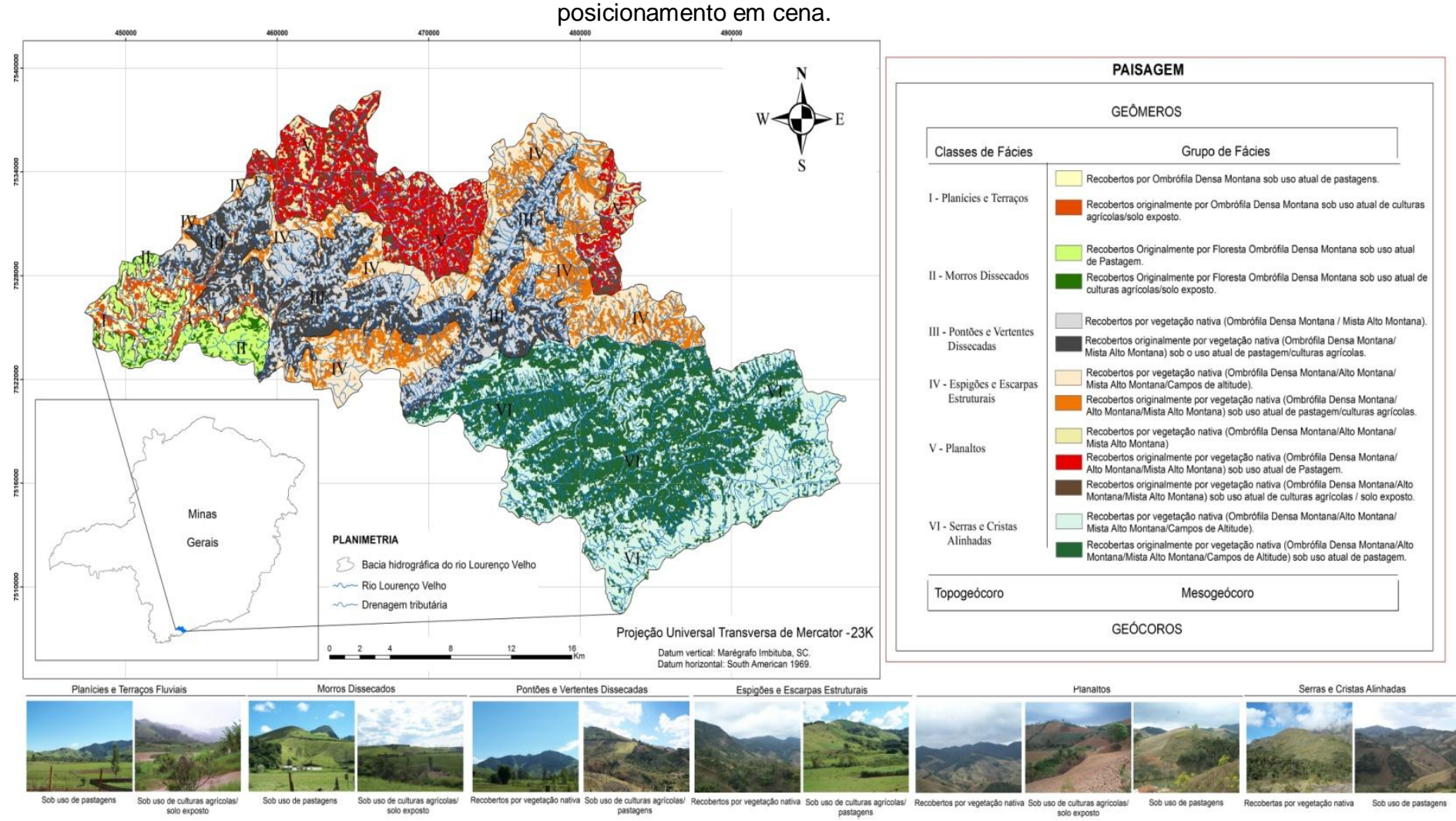

Fonte: $O$ autor. 


\section{CONSIDERAÇÕES FINAIS}

Os geossistemas oferecem a oportunidade de visualização da dinâmica existente na bacia hidrográfica a partir da análise integrada de seus elementos. Além disso possuem uma estrutura de análise concreta e, ao mesmo tempo adaptável a bacias hidrográficas com dimensões variadas sendo, portanto, extremamente versátil no que toca às escalas de abordagem. Os elementos de análise, podem se mostrar mais ou menos evidentes de uma bacia hidrográfica para outra, porém estão sempre em interação e reproduzem mosaicos de superfície a partir das suas relações verticais, processadas pela troca de energia entre tais elementos. Nesse contexto, o estudo geossistêmico aqui apresentado descortinou a dinâmica da paisagem na bacia hidrográfica do rio Lourenço Velho, expondo a tênue relação existente entre o ambiente natural, que ainda resiste e é representativo em mosaicos de grupos de fácies pertencentes a algumas classes de fácies e, entre esse mesmo ambiente sob intervenção antrópica, representado por grupos de fácies que ocorrem em todas as classes de fácies.

A adoção da fragilidade ambiental como elemento verificador das relações entre as unidades geossistêmicas diante da integração dos dados de declividade, uso da terra e solos, com ajustes efetuados pelo levantamento pré-paisagístico, permitiu a visualização da dinâmica da paisagem na unidade de área selecionada. Sendo assim, afirma-se que a fragilidade ambiental tem potencial para ser utilizada como elemento complementar aos estudos que se voltam à investigação sobreo dinamismo existente em unidades geossistêmicas da paisagem.

De forma geral, observou-se que as declividades e uso da terra balizaram a fragilidade ambiental nas unidades sistêmicas mapeadas, comportando-se como catalizadoras dos fluxos energéticos na bacia hidrográfica do rio Lourenço Velho. Onde a opção antrópica foi a retirada da vegetação natural e a introdução de pastagens e cultivos agrícolas a fragilidade ambiental mostrou aumento significativo, resposta sistêmica à alteração no input energético. Em áreas de ocorrência dos cambissolos os processos erosivos se mostraram mais veementes quando em contato com as atividades agrosilvopastoris e onde, consequentemente, são registradas as classes mais elevadas de fragilidade ambiental.

Os resultados apresentados, erigidos a partir de um método de análise genuinamente geográfico, trazem máxima contribuição ao entendimento da dinâmica das paisagens inseridas no contexto montanhoso de Brasil Sudeste e contribuem com reflexões futuras relacionadas ao jogo sistêmico imposto pela ação do homem sobre o meio em que vive.

Dada a importância regional da bacia hidrográfica do rio Lourenço Velho, a sua extensão em área, que abrange terrenos de sete municípios e a diversidade de usos da terra em conflito com as características físico-naturais a ela concernentes, as informações aqui prestadas comportam-se como balizadoras aos trabalhos futuros que vislumbrem o planejamento ambiental da bacia e incitam reflexões sobre a necessidade de ações intermunicipais conjuntas visando adequar o manejo das unidades de paisagem mapeadas por meio da compreensão da dinâmica que se processa nos intradomínios de cada uma dessas unidades.

\section{AGRADECIMENTOS}

À Fundação de Amparo à Pesquisa do Estado de São Paulo - FAPESP pelo financiamento de parte do trabalho, por meio de concessão de bolsa de pesquisa - Processo 2010/52681-3.

\section{REFERÊNCIAS}

BATISTA, J. P. G.; SILVA, F. M. Avaliação da fragilidade ambiental na microbacia do riacho Cajazeiras no semiárido Potiguar. Boletim Goiano de Geografia, Goiânia, vol. 33, núm. 1, janeiro-abril, 2013, pp. 63-82. https://doi.org/10.5216/bgg.v33i1.23632

BERTRAND, G. Le paysage entre la Nature et la Société. Revue Géographique Des Pyrénées Et Du Sud-ouest, Toulouse, v. 49, n. 2, p.239-258, 1978.

https://doi.org/10.3406/rgpso.1978.3552 
BRASIL. Lei n. 9.433/97, de 8 de janeiro de 1997. Disponível em < http://www.planalto.gov.br/ccivil_03/leis/l9433.htm>. Acesso em 26 de maio de 2019.

BRASIL. Conselho Nacional do Meio Ambiente-CONAMA. Resolução n.001, de 23 de janeiro de 1986. Disponível em <http://www2.mma.gov.br/port/conama/res/res86/res0186.html>. Acesso em 26 de maio de 2019.

BRASIL. Lei no 6.938, de 31 de agosto de 1981. Disponível em < http://www.planalto.gov.br/ccivil_03/leis/l6938.htm>. Acesso em 26 de maio de 2019.

CAVALCANTE, J. C. et al. Projeto Sapucaí: relatório final de geologia. São Paulo: DNPM/CPRM, 1979. 299 p.

CAVALCANTI, L. C. S.; CORREA, A. C. B. Geossistemas e Geografia no Brasil. Revista Brasileira de Geografia, vol. 61, n. 2, p. 1-33, 2017. https://doi.org/10.21579/issn.2526-0375 2016 n2 p3-33

CPRM - Serviço Geológico do Brasil. Mapas estaduais de geodiversidade: Minas Gerais. Rio de Janeiro: CPRM, 2006. 1 v. Documento cartográfico em arquivo vetorial. Disponível em: <geobank.sa.cprm.gov.br>. Acesso em: 11 fev. 2017.

CPRM - Serviço Geológico do Brasil. Mapas Geológicos: SF. 23-Y-B-III -Itajubá. Rio de Janeiro: CPRM, 2008. 1 v. (Parcerias com universidades). Documento cartográfico em arquivo shape, acompanhado de relatório técnico. Disponível em: <geobank.sa.cprm.gov.br>. Acesso em: 11 fev. 2017

DE MARTONNE, E. Problemas Morfológicos do Brasil Tropical Atlântico. Revista Brasileira de Geografia, IBGE, Rio de Janeiro, v. 5, n. 4, p.3-28, 1943.

DEMEK, J. The landscape as a geosystem. Geoforum, vol. 9, pp 29-34, 1978. https://doi.org/10.1016/0016-7185(78)90022-2

DOLFUSS, O. A Análise Geográfica. São Paulo: Difusão Europeia do Livro, 1973. $130 \mathrm{p}$.

GANZEI, K. S.; YERMOSHIN, V. V; MISHINA, N. V. The dynamics of land use within the Amur basin in the 20th century. Geography and Natural Resources, vol. 31, p.1824, 2010.

https://doi.org/10.1016/j.gnr.2010.03.004

K. S. The geosystems of the Southern and Middle Kuril Islands. Geography and Natural Resources, vol. 29, p.251-255, 2008.

https://doi.org/10.1016/j.gnr.2008.09.009

HAASE, G. Medium scale landscape classification in the German Democratic Republic. Landscape Ecology, Tempe (AZ), v. 3, n. 1, p.29-41, 1989. https://doi.org/10.1007/BF00157754

IBGE - Instituto Brasileiro de Geografia e Estatística. Cartas, Mapas e Cartogramas. Disponível em: < https://loja.ibge.gov.br/cartas-mapas-e-cartogramas>. Acesso: em 05 de maio de 2011.

Manual Técnico de Geomorfologia. Rio de Janeiro: IBGE, Departamento de Recursos Naturais e Estudos Ambientais, 2009. 175 p.

Mapa de Biomas e de Vegetação. Rio de Janeiro: IBGE, 2004. Disponível em: < https://ww2.ibge.gov.br/home/presidencia/noticias/21052004biomas.shtm>. Acesso em: 18 jun 2017.

. Manual Técnico da Vegetação Brasileira. Rio de Janeiro: IBGE, 1992. 98 p.

ISACHENKO, G. A. Long-term conditions of Taiga landscapes of European Russia. In: DYAKONOV, K. N.; KSIMOV, N. S.; KHOROSHEV, A. V.; KUSHLIN, A. V. Landscape analysis for sustainable development: teory and applications of landscape science in Russia. Moscow: Alex Publischers, 2007.

KUZMENKO, E. I. Cartographic Approach in Studying the Structure and Dynamics of Geosystems as Exemplified by the Middle Ob Region. Geography and Natural 
Resources, vol. 32, no. 2, pp. 184-189, 2011. https://doi.org/10.1134/S1875372811020144

MAGALHÃES JUNIOR, A. P.; DINIZ, A. A. Padrões e direções de drenagem na bacia do rio Sapucaí - Sul de Minas Gerais. Geonomos, Belo Horizonte, v. 5, n. 2, p.29-32, 1997. Disponível em <

https://periodicos.ufmg.br/index.php/revistageonomos/issue/view/621>. Acesso em: 08 nov. 2017.

https://doi.org/10.18285/geonomos.v5i2.180

MARQUES NETO, R. Geomorfologia e Geossistemas: influências do relevo na definição de unidades de paisagem no maciço alcalino do Itatiaia (MG/RJ). Revista Brasileira de Geomorfologia (online), vol. 17, n.4, p. 729-742, 2016.

https://doi.org/10.20502/rbg.v17i4.907

MARQUES NETO, R.; OLIVEIRA, G. C.; DIAS, J. S. Geossistemas em ambientes montanhosos: a revelação da paisagem na serra do Caparaó (MG/ES). Ra'E Ga, Curitiba, v.38, p. 267-288, 2016. https://doi.org/10.5380/raega.v38i0.43740

MARQUES NETO, R.; PEREZ FILHO, A.; OLIVEIRA, T. A. Geossistemas na bacia do Rio Verde (MG): proposta de mapeamento de sistemas ambientais físicos em escala regional. Geografia, Rio Claro, v. 39, n. 2, p. 321-336, 2014.

MEIRELLES, M. S. P.; CAMARA, G.; ALMEIDA, C. M. Geomática: modelos e aplicações ambientais. Brasília: Embrapa Informação Tecnológica, 2007.

NAKASHIMA, M. S. R. Carta de fragilidade ambiental da bacia do rio Keller, estado do paraná: subsídio ao estudo dos processos erosivos. Acta Scientiarum, Maringá, v. 23, n. 6, p.1547-1560, 2001.

NASA - National Aeronautics and Space Administration. Advanced Spaceborne Thermal Emission and Reflection Radiometer. Disponível em:

$<$ https://asterweb.jpl.nasa.gov/data.asp>. Acesso em 13 de julho de 2017.

OLIVEIRA, P. C. A. de; RODRIGUES, G. S. de S. C.; RODRIGUES, S. C. Fragilidade Ambiental e uso do solo da bacia hidrográfica do córrego Pindaíba, Uberlândia, MG, Brasil. Revista Ambiente e Água: an interdisciplinary journal of applied science, Taubaté, v. 3, n. 1, p.54-67, 2008.

https://doi.org/10.4136/ambi-agua.42

PLYUSNIN, V. M.; DROZDOVA, O. V.; KITOV, A.D.; KOVALENKO, S.N. The dynamics of mountain geosystems in southern Siberia. Geography and Natural Resources, vol. 29, p. 103-109, 2008.

https://doi.org/10.1016/j.gnr.2008.06.019

RODRIGUEZ, J. M. M; SILVA, E. V. Planejamento e Gestão Ambiental: subsídios da geoecologia das paisagens e da teoria Geossistêmica. Fortaleza: Edições UFC, 2013. $370 \mathrm{p}$.

RODRIGUEZ, J. M. M.; SILVA, E. V. da; CAVALCANTI, A. P. B. Geoecologia das Paisagens: uma visão geosssitêmica da análise ambiental. Fortaleza: Edições UFC, 2007.

ROSS, J. L. S. Análise Empírica da Fragilidade dos Ambientes Naturais e Antropizados. Revista do Departamento de Geografia- FFLCH-USP, São Paulo n. 8, p 63-74, 1994.

https://doi.org/10.7154/RDG.1994.0008.0006

. J. L S. O registro cartográfico dos fatos geomórficos e a questão da taxonomia do relevo. Revista do Departamento de Geografia- FFLCH-USP, São Paulo, n. 10, p.41-58, 1992.

ROUGERIE, G.; BEROUTCHACHVILI, N. Géosystèmes et Paysages: bilan et méthodes. Paris: Armand Colin, 1991. 302 p.

SAUSHKIN, Y G; SMIRNOV, A M. Geosystems and Geostructures. Soviet 
Geography: review and translation, New York, v. 11, n. 3, p.149-154, mar. 1970. https://doi.org/10.1080/00385417.1970.10770471

, Yu. G. The interaction of nature and society. Soviet Geography: review and translation, New York, v. 5, n. 12, p.39-45, Feb. 1964.

https://doi.org/10.1080/00385417.1964.10770138

SOARES, P. C.; FIORI, A. P. Lógica e sistemática na análise e interpretação de fotografias aéreas em geologia. Notícia Geomorfológica, Campinas, v.16, n.32, p.71104, 1976.

SOTCHAVA, V. B. Por uma teoria de classificação de geossistemas de vida terrestre. Biogeografia, São Paulo, n 14, p.1-24, 1978 .

. V. B. Introducción a la doctrina sobre los geosistemas. Novosibirsk: Editora Nauka, filial de Siberia, 1978b. 318 p. (em russo) p.1-50, 1977.

V. B. O Estudo de Geossistemas. Métodos em Questão, São Paulo, n. 16,

. V. B. Theoretical requisites for the mapping of the human habitat. Soviet Geography: review and translation, New York, v. 16, n. 2, p.86-96, Feb. 1975. https://doi.org/10.1080/00385417.1975.10640055

. V. B. A new work on theoretical geography. Soviet Geography: review and translation, New York, v. 15, n. 5, p.311-319, May 1974.

https://doi.org/10.1080/00385417.1974.10770673

. V. B. Geography and Ecology. Soviet Geography: review and translation, New York, v. 12, n. 5, p.277-292, May 1971.

https://doi.org/10.1080/00385417.1971.10770247

V. B. Les Principes de la division physico-géographique des territoires. In: ACADÉMIE des SCIENCES de L'URSS / SOCIÉTÉ de GEOGRAPHIE de L'URSS. Essais de Géographie. Léningrad: Académie des Sciences de l'URSS, 1956, p. 372382.

UFV - Universidade Federal de Viçosa. Mapa de solos do estado de Minas Gerais: legenda expandida. Belo Horizonte: Fundação Estadual do Meio Ambiente, 2010. 49 p. Acompanha mapa na escala 1:650.000.

YEFREMOV, Yu. K. The landscape sphere and the geographical environment. Soviet Geography: review and translation, New York, v. 10, n. 45, p.248-254, May 1969. https://doi.org/10.1080/00385417.1969.10770408

, Yu. K. The place of physical geography among the natural sciences. Soviet Geography: review and translation, New York, v. 5, n. 2, p.3-10, Feb. 1964. https://doi.org/10.1080/00385417.1964.10770061

Recebido em: 15/01/2019

Aceito para publicação em: 29/05/2019 